\title{
LAVOURA ARCAICA DE RADUAN NASSAR: UMA POSSIBILIDADE PARA A LEITURA DO MUNDO CONTEMPORÂNEO
}

\author{
CULTIVO DE ARCHAIC RADUAN NASSAR: UNA OPORTUNIDAD PARA EL \\ MUNDO CONTEMPORÁNEO DE LECTURA
}

\author{
RADUAN NASSAR'S ARCHAEAL CLEARANCE: A POSSIBILITY FOR READING \\ THE CONTEMPORARY WORLD
}

\author{
Sandra Aparecida Pires FRANCO ${ }^{1}$ \\ Cyntia Graziella Guizelim Simões GIROTTO² \\ Maria Luzia Silva MARIANO ${ }^{3}$
}

RESUMO: Objetiva-se neste texto analisar a obra Lavoura Arcaica (1989), de Raduan Nassar como uma possibilidade para uma nova leitura do mundo contemporâneo. A leitura de mundo advém da maneira como o autor interpreta e vive a realidade social em que está inserido. A obra Lavoura Arcaica trata-se de um texto literário de produção pós-moderna da literatura brasileira. Dessa forma, o presente trabalho refere-se a uma pesquisa documental, que aborda a análise da obra literária expondo sua estrutura e seu contexto social. Os pressupostos teóricos estão pautados no materialismo histórico e dialético. A análise da obra literária possibilitou compreender que o autor tem a possibilidade de recriar a realidade, por meio do reflexo estético, levando ao leitor à apropriação de conhecimentos de diferentes tempos e espaços.

PALAVRAS-CHAVE: Possibilidades de leitura. Leitura de mundo. Texto literário.

RESUMEN: El objetivo es analizar el trabajo en este texto a la izquierda del padre (1989) de Raduan Nassar como una posibilidad para una nueva lectura del mundo contemporáneo. El mundo de la lectura proviene de la forma en que el autor interpreta y vive la realidad social en la que aparece. La izquierda del Padre trabajar es un texto posmoderno producción literaria de la literatura brasileña, el tiempo se refleja en el fin de las ideologías dominantes y pérdida de referencias, la denuncia de la crisis existencial del sujeto. Por lo tanto, en este documento se refiere a la investigación documental, que aborda el análisis de la obra literaria la exposición de su estructura y su contexto social. Los supuestos teóricos son guiados por el materialismo histórico y dialéctico. El análisis de la obra literaria nos ha permitido entender que el autor tiene la capacidad de recrear

\footnotetext{
${ }^{1}$ Universidade Estadual de Londrina (UEL), Londrina - PR - Brasil. Pós-Doc em Educação. Programa de Pós-Graduação em Educação da Universidade Estadual de Londrina. E-mail: sandrafranco26@ hotmail.com ${ }^{2}$ Universidade Estadual Paulista (UNESP), Marília - SP - Brasil. Livre Docência em Educação. Programa de Pós-Graduação em Educação da Universidade Estadual Paulista "Júlio de Mesquita Filho". E-mail: cyntia@marilia.unesp.br

${ }^{3}$ Universidade Estadual de Londrina (UEL), Londrina - PR - Brasil. Doutoranda em Educação. Programa de Pós-graduação em Educação da Universidade Estadual de Londrina. E-mail: malumariano@yahoo.com.br
} 
la realidad a través de la reflexión estética, lo que lleva al lector a la apropiación de los conocimientos en diversos tiempos y espacios.

PALABRAS CLAVE: La lectura de posibilidades. Lectura mundo. Texto literário.

ABSTRACT: The objective of this text is to analyze the work of Archaic Lavoura, (1989) by Raduan Nassar as a possibility for a new reading of the contemporary world. The world reading comes from the way the author interprets and lives the social reality in which it is inserted. The work Lavoura Arcaica is a literary text of postmodern production of Brazilian literature, at which time it was reflected on the end of dominant ideologies and loss of references, denouncing the existential crisis of the subject. In this way, the present work refers to a documentary research, that approaches the analysis of the literary work exposing its structure and its social context. The theoretical assumptions are based on historical and dialectical materialism. The analysis of the literary work made it possible to understand that the author has the possibility of recreating reality through aesthetic reflection, leading the reader to appropriate knowledge of different times and spaces.

KEYWORDS: Reading possibilities. World reading. Literary text.

\section{Introdução}

No contexto da chamada produção pós-moderna na literatura brasileira, existe uma polêmica diante do termo pós-moderno, principalmente nas décadas de 70 e 80, quando houve momentos em que se discutiu sobre as transformações na literatura, refletindo sobre o fim de ideologias dominantes e perda de referenciais, denunciando a crise do sujeito.

A literatura torna-se então um rico material de análise, possibilitando verificar detalhes, momentos nunca registrados em livros documentais e/ou de história. Devido e com as transformações sociais, em âmbitos gerais, as grandes transformações históricas, políticas e econômicas, proporcionaram ver um homem destituído de seus princípios. Frente a essas transformações, as obras literárias registram momentos que não serão mais vivenciados.

Nesse sentido, o objetivo deste texto é o de analisar a obra literária Lavoura Arcaica (1989), de Raduan Nassar. Para tanto, faz-se necessário compreender o porquê de determinado escritor relatar suas histórias de acordo com a tendência da época e como a obra Lavoura Arcaica se apresenta neste contexto.

Importante salientar que, decorrente dessas alterações, o homem começou a expressar na literatura a visão do momento. De acordo com Freire (1989), a visão de

RIAEE - Revista Ibero-Americana de Estudos em Educação, Araraquara, v. 13, n. 2, p. 885-897, abr./jun., 2018. E-ISSN: $1982-5587$. 
mundo, ou seja, leitura de mundo, antecede a leitura da palavra. Dessa forma é possível inferir que a literatura passou a ser instrumento para se retratar a realidade social, política e econômica em que a sociedade está inserida.

Em especial, para este texto, no final de século XIX e início do XX, o homem defronta-se com uma sociedade que o impossibilita compreender o total. Ocorrem revoluções industriais, o homem não tem mais tempo para refletir, para pensar, o futuro o pressiona com uma velocidade incrível. O escritor, então, que está diante dessa nova situação, faz o registro.

\section{A literatura e suas alterações temporais}

Em termos literários, Rosenfeld (1969) verificou que em Lavoura Arcaica estamos diante do romance moderno. O crítico literário moderno não se dispõe de meios adequados para analisar o novo tipo de romance, pois o homem moderno está perante o caos do mundo contemporâneo. Não se trata mais do mundo empírico, trata-se da desrealização, é uma realidade apreendida pelos nossos sentidos. Até mesmo a perspectiva desaparece, o narrador se omite, envolvendo-se com a personagem e ironizando a perspectiva convencional.

Para Rosenthal (1975), trata-se de uma realidade flutuante, uma consciência nova, apresentando uma nova verdade ou realidade, sendo ela a do romancista ou a do mundo. Percebemos por meio do romance moderno que o modo como se escreve reflete esse novo mundo, havendo a adaptação a essa imagem.

No século XX, o mundo apresenta-se incompreensível, ambíguo, e a linguagem apresentada nos romances é reflexo de sua época. Assim, percebe-se o leitor experimentando a insegurança do romance moderno, confundindo o mundo psíquico com o mundo interior, resultando o contexto em monólogos. Dessa forma, a literatura possibilita ao leitor uma reflexão sobre a sua própria condição humana frente às transformações modernas. O espaço e o tempo são questionados por diversos autores e críticos literários.

Vale lembrar que diante de uma sociedade capitalista, pós-industrial, o leitor deve localizar-se historicamente para poder perceber o ambiente em que vive e como se dão as relações sociais nesta sociedade. A linguagem é o único meio possível para que o sujeito que se encontra em conflito com o meio em que vive comece a recompor suas atitudes. 
Percebe-se que os autores começaram a refletir sobre a tendência do momento, procurando usar da paródia, com o uso frequente da metalinguagem.

Dessa forma, a obra Lavoura Arcaica de Raduan Nassar, apresenta em sua narrativa o neobarroco. Percebemos que a história é estruturada a partir de um trabalho com a linguagem, apresentando diversos gêneros textuais. A obra parece estar fragmentada, mas está permeada de uma lógica de significações. Chiampi (1998) vê, no barroco, estratégias para salvar uma modernidade estética em agonia. Nesta perspectiva, propõe uma reciclagem do barroco histórico com perspectiva pós-moderna, para extrair dele a representação do paradoxo, do artifício, da teatralização. Seria atravessar a modernidade.

Por meio da linguagem, conseguimos identificar a artificializacão expressa na obra. Assim, podemos analisar a obra, explicitando como se vislumbra a tendência neobarroca no contexto da ficção pós-moderna. Não só histórica e socialmente é possível fazer essa análise, como também verificar o papel da arte nesta sociedade pós-moderna, nesta época em que o sujeito como ser desaparece. Podemos citar que existe uma polêmica sobre a existência ou não do termo pós-modernismo, procuraremos apresentar aqui mais uma argumentação acerca do assunto, proposta por Jameson (1997). Seu texto A lógica cultural do capitalismo tardio (1997) apresenta a justificativa de que para existir o pós-modernismo era preciso ter ocorrido um desgaste muito grande com as obras feitas no Modernismo.

Segundo o texto de Jameson (1997), foi na arquitetura, uma manifestação artística, que se evidenciou as maiores mudanças. Percebe-se segundo o texto que em termos literários há uma preferência por filmes, anúncios, biografias populares, história de mistério e romances de fantasia. Essa preferência só pode ser confirmada quando notamos que esse novo fascínio não é só em âmbito cultural, mas sim que existe uma grande relação com a sociologia e, principalmente, com a sociedade de consumo, eletrônica e de informação. Não se trata de uma relação com o capitalismo clássico, mas sim, com a nova fase social apresentada, ou seja, com o capitalismo tardio.

No texto de Jameson (1997), observamos que há uma concepção histórica presente em sua polêmica, mencionada anteriormente. Há, até mesmo, um questionamento se o pósmodernismo não é um estágio do modernismo. Interessante mantermos a relação exposta por Jameson (1997), ou seja, a produção estética do pós-modernismo não escandaliza a mais ninguém, pode-se falar sobre qualquer assunto, vemos então que a produção estética está vinculada à produção de mercadorias. Arte e economia estão interligadas no texto de Jameson (1997), o que não deixa de ser verdade, pois a arte é uma expressão de uma nova 
dominação ou relação social. Devemos deixar claro que a questão do capitalismo tardio demonstra a transformação na sociedade contemporânea, o que nos confirma que a arte produzida até então, ou seja, no modernismo, realmente não atende a essa nova relação social.

Podemos, assim, notar que suas considerações finais apontam para a concepção de pós-modernismo como uma concepção histórica e não somente estilística. Trata-se, pois, de uma visão de estilo e não isoladamente de uma visão da lógica do capitalismo tardio, havendo neste último a necessidade de uma mutação na cultura do capitalismo tardio, que não sabemos qual será. Sabemos apenas que precisamos mudar o nosso modo de agir, que parece estar estática perante esse espaço de confusão social.

\section{Lavoura Arcaica: sua contextualização}

Raduan Nassar é o sétimo filho de imigrantes libaneses que vieram para o Brasil em 1920. Nasceu em 1935 em Pindorama, cidade do interior do estado de São Paulo. Desde os primeiros anos escolares Raduan teve contato com as obras literárias, sendo chamado com frequência para recitar poesias nas datas comemorativas, pois possuía excelente memória. Muda-se com a família para São Paulo em 1953 e conclui o curso colegial no ano seguinte, ingressando em 1955 no curso de Direito na Faculdade de Direito do Largo de São Francisco e no curso de Letras Clássicas da Faculdade de Filosofia, Ciências e Letras da Universidade de São Paulo (USP).

Raduan se formou em Filosofia em 1963 e em 1968 faz as primeiras anotações do que viria a ser o romance Lavoura Arcaica, publicado somente em 1975 pela Companhia das Letras. A obra apresenta duas partes: a Partida e o Retorno. A partida é dividida em 21 capítulos e o retorno em 9 capítulos. A obra foi adaptada para o cinema, em 2001, pelo diretor Luiz Fernando de Carvalho, com trilha sonora de Marco Antônio Guimarães.

Sarduy (1979), em seus escritos, propicia um caminho de leitura para a obra Lavoura Arcaica, em que a leitura se faz com a releitura do passado, só que em contextos diferentes. O que percebemos é um trabalho com a linguagem e uma preocupação profunda com os processos de composição do texto, com jogo de palavras e diversos ângulos. A palavra, de acordo com Bakhtin (1997), atua como elemento formador e transformador do sujeito, pois é carregada de fenômenos ideológicos, sejam eles de cunho religioso, moral, político, social, etc. 
Dessa forma, é possível perceber por meio das narrações de André, o filho rebelde que sai de casa, e também nos seus diálogos com o pai, a moral religiosa predominante na família. A ordem que predomina é a patriarcal, sendo possível perceber tal fato quando André narra a disposição da família ao se sentar à mesa:

Eram esses os nossos lugares à mesa na hora das refeições, ou na hora dos sermões: o pai à cabeceira; à direita por ordem de idade, vinha o primeiro o Pedro, seguido de Rosa, Zuleika e Huda; à sua esquerda, vinha mãe, em seguida eu, Ana, e Lula, o caçula. (NASSAR, 1989, p. 156).

O pai, sentado à cabeceira da mesa, representa a autoridade, a ordem que precisa ser seguida. À direita do pai senta-se Pedro, o filho mais velho e consequentemente o seu sucessor, e logo após Pedro os irmãos mais velhos, que se submetem aos desígnios do pai sem questionamentos. À esquerda sentam-se os que podem ser considerados os transgressores, a mãe que com o excesso de carinho 'estraga' os filhos. Ao lado da mãe encontram-se os filhos mais novos, que sentem vontade em romper com a ordem imposta pelo pai, com o marasmo da vida na fazenda e até mesmo com os preceitos religiosos (COELHO, 2010).

A estética neobarroca se enquadra às contradições, principalmente quando tempo, espaço e movimento são anulados e a noção de eu perde-se em meio aos conflitos resultantes da modernidade. Essa estética parece a expressão mais adequada para a representação do momento caótico pelo qual a sociedade capitalista vigora. De acordo com Sirino (2008), as identidades tradicionais que unificavam o sujeito se perdem com o advento da modernidade, fragmentando o sujeito moderno, deixando de lado antigos valores religiosos, étnicos, políticos, raciais, sexuais, de gênero ou de classe social.

A família de André, apesar de estar inserida nessa sociedade moderna, que apresenta novos valores e novos padrões aos sujeitos, ainda conserva os costumes de uma família patriarcal que vive no meio rural. André rompe com esses valores tradicionais ao deixar a família e se mudar para o meio urbano e também ao nutrir uma paixão por sua irmã Ana. André representa de forma clara esses valores que vão sendo esquecidos e dão lugar à nova ordem social e econômica que se estabelece na sociedade moderna capitalista.

A obra apresenta uma versão da parábola bíblica: a do Filho Pródigo, que aparece invertida, pois é Pedro, o irmão, natural substituto do pai, quem vai buscá-lo. Interessante observar que o nome Pedro sugere aquele que vai à frente, por ser Pedro quem foi ordenado por Deus para encaminhar seu povo. 
Notamos que em Lavoura Arcaica, a sintaxe ordena o som e o sentido do texto. André se sente excluído: “dos que trazem um sinal na testa”. (NASSAR, 1989, p.139). Süssekind (1985) observa esta intratextualidade quando menciona que em Lavoura Arcaica, Raduan Nassar apresenta o fascinante:

[...] jogo envolvendo uma ação narrativa reduzida quase ao ponto zero [...], um aumento vertiginoso dos parênteses, de falas que se sucedem quase sem parágrafos, vazios e intervalos capazes de torna-las menos abafadas, de palavras que se multiplicam torrencialmente; numa bela tensão entre o não dito (plural) e o vivido, o presente do texto (restrito), entre a imobilidade no contexto da ação e a rapidez com que se sucedem os mais diversos acontecimentos e sensações no plano imaginário. E a possibilidade sempre presente de os dois planos se cruzarem com resultados inesperados. (SÜSSEKIND, 1985, p. 10).

Temos exemplos de capítulos inteiros entre parênteses, como os décimo, décimo segundo e décimo quinto. Encontramos também um trecho de poesia concreta no capítulo vinte e nove.

Pai! e de outra voz, um uivo cavernoso, cheio de desespero Pai! e de todos os lados, de Rosa, de Zuleika e da Huda, o mêsmo gemido desamparado

Pai!

eram balidos estrangulados Pai! Pai! (NASSAR, 1989, p.193).

Notamos, na obra, que André retoma frases mencionadas em outros capítulos, como exemplo, ao início do nono, retoma o final do sétimo, repetindo as mesmas palavras, após falar ao irmão sobre a sua anomalia, a epilepsia, relembrando a figura do pai: "[...] que rostos mais coalhados [...]: o pai à cabeceira, o relógio de parede às suas costas, cada palavra sua ponderada pelo pêndulo, e nada naqueles tempos nos distraindo tanto como os sinos graves marcando as horas". (NASSAR, 1989, p. 49). A obra apresenta metáforas, sinestesias, aliterações, trabalhando muito com a sonoridade: "as asas úmidas e silenciosas de uma brisa azul”. (NASSAR, 1989, p. 51).

A obra é um resultado de uso da linguagem que decorrente da narrativa; nos permite questionar sobre os valores sociais sobre o que é proibido. Trata-se de um "drama 
tenebroso, em estilo incisivo, nunca palavras ou decorativo, da eterna luta entre a liberdade e a tradição", da liberdade almejada por André e da tradição do pai, nos seus sermões. Entretanto, André quer fazer parte da ordem, principalmente quando conversa com Ana sobre os seus ideais:

[...] querida irmã, vou amaciar as minhas faces, abandonar meu isolamento, minha mudez, o meu silêncio, vou estar bem com cada irmão, misturar minha Vida à vida de todos eles, hei de estar sempre presente na mesa clara onde a família se alimenta; vou falar sobre coisas simples como todos falam, dizer para o vizinho da campina, por exemplo, que as safras do ano prometem. (NASSAR, 1989, p. 127).

André quer se integrar ao mundo, num diálogo entre o passado e o presente no qual detectamos pelas falas que estão em sua memória. Em suma, podemos evidenciar que Lavoura Arcaica é uma obra pós-moderna, por apresentar a descentralização do sujeito, mas ao mesmo tempo apresenta conteúdo e forma. Percebemos com a leitura do texto que o seu objeto de análise, especificamente, é expor sobre a subjetividade. Isso é o que lhe interessa, e não o sujeito. O que interessa é como a subjetividade aponta para a desconstrução da crença num sujeito natural.

Para Lukács (1970), a arte é uma das objetivações mais elevadas do homem. A arte originou-se da atividade de transformação da natureza por meio do trabalho. Para o autor, a arte revive o passado e também representa o que é particular de cada indivíduo, "por isso podemos reviver essa transcendência nas obras do passado, mas a revivemos como destino humano, sob a forma de emoções e paixões humanas" (p. 283). A arte, assim como a ciência e a filosofia, poderá contribuir para mudar a sociedade vigente, para uma nova visão de mundo, movendo a consciência para além do imediatismo da vida cotidiana alienada.

O papel educativo da arte para Lukács (1970) é quando a elevação da individualidade vai acima das circunstâncias particulares da vida cotidiana do sujeito. Por meio da arte, o homem pode reviver tramas humanos que se apresentam distantes no tempo e no espaço, daquilo que lhe é familiar. As obras estético-literárias trazem para a vida das pessoas experiências humanas intensificadas que movimentam a subjetividade para além da cotidianidade, aproximando-se da personalidade e da realidade social.

Duarte e Ferreira (2011, p. 117) citam Lukács ao afirmar que a obra de arte é parte da essência da realidade humana: 
O que Lukács defende é que a obra de arte, quando alcança uma relação ótima entre conteúdo e forma, dispensa justificativas externas, ela fala por si mesma e, contraditoriamente, ao fazer isso, ela se conecta à história da humanidade.

Lavoura Arcaica é essa arte que expressa em um texto em que se entrelaçam o novelesco e o lírico, por meio de um narrador em primeira pessoa, André, o filho encarregado de revelar o avesso da imagem da família. A obra é sobretudo uma aventura com a linguagem: além de fundar a narrativa, a linguagem é também o instrumento que, com seu rigor, desorganiza um outro rigor, o das verdades pensadas como irremovíveis.

A obra inicia-se com André, narrador-personagem, se masturbando e sendo interrompido pelo irmão que viera buscá-lo. Percebemos uma grande diferença entre os dois. André é o que representa a desordem, o marginal, e Pedro, seu irmão, a ordem. Por meio da leitura, entramos em contato com o passado de André com as lembranças do local onde moravam, da sua família, dos sermões, do local onde sentavam, de seus valores familiares, da tradição. Percebemos na obra André descobrindo o amor, os desejos escondidos e o refúgio na casa velha, da relação com a mãe e os sermões do pai, além de reflexões sobre o tempo, diferentes das do pai e a confissão a Pedro do incesto com Ana, sua irmã.

O mesmo acontece com o capítulo vinte e nove, momentos antes de narrar a morte de Ana, quando ele recupera um longo trecho do capítulo quinto, narrando sua fuga para o meio do bosque, de onde ficava a observá-la, dançando descalço ia: “[...] afastando as folhas secas e alcançando abaixo delas a camada de espesso húmus, a minha vontade incontida era de cavar o chão com as próprias unhas e nessa cova me deitar à superfície e me cobrir inteiro de terra úmida [...]". (NASSAR, 1989, p. 191). Podemos perceber que a cena é a mesma. A primeira dança revela o desejo e a fixação dele pela irmã; e a segunda, como se fosse repetição daquela, anuncia e confirma a tragédia que se abaterá sobre a família.

Devemos dar destaque ao que Sarduy (1979) comenta sobre a proliferação de imagens, quando André demonstra o caráter do erotismo, presente em todas as lembranças e atos do narrador. Assim como os elementos terra, úmido, cheiro, húmus, folhas dão conta de mostrar a busca pelo prazer, num processo de busca de si mesmo. Podemos notar que todas as enumerações de significados apresentados em imagens repetidas como casa velha x casa nova, capela, cheiros, nos é revelado para alcançarmos uma leitura mais clara. 
Novamente um destaque para a forma na segunda parte: O Retorno, em que André regressa e podemos observar o uso do discurso direto, quando ele conversa com o pai e com o irmão Lula, a quem admira por ter os olhos parecidos com os de Ana. André procura explicar o porquê de sua partida para o pai, mas aquele não o entende. André recua e o pai o perdoa. Perdão, na verdade, sem importância.

Eu também tenho uma história, pai, é também a história de um faminto, que mourejava de sol a sol sem nunca conseguir aplacar sua fome, e que de tanto se contorcer acabou por dobrar o corpo sobre si mesmo alcançando com os dentes as pontas dos próprios pés; sobrevivendo à custa de tantas chagas, ele só podia odiar o mundo.

[...]

Nada te faltava. Por tudo isso, ponha de lado essas histórias de famintos... (NASSAR, 1989, p. 159-160).

O desfecho ocorre com a tragédia da morte de Ana que, coberta pelas “quinquilharias do mundo", acumuladas por André em uma caixinha, dançava sensualmente: "[...] carregue essas miudezas todas pra casa e conte entre olhares de assombro como foi se erguendo a história do filho e a história do irmão”. (NASSAR, 1989, p. 74).

Após tomar conhecimento do incesto, o pai a mata e provoca a desintegração da família. Pelas mãos daquele que em seus sermões pregava a ordem, a tradição da “[...] terra, o trigo, o pão, a mesa, a família (a terra), existe neste ciclo, dizia o pai nos seus sermões, amor, trabalho, tempo.” (NASSSAR, 1989, p. 183). Percebemos então, a verdade absoluta do pai.

Percebemos que o retorno de André deveria trazer a paz à família, mas acaba por inaugurar a desintegração dela. Fica claro que a obra apresenta a questão de que sempre obedecemos a sacramentos, tradições, que nos tiram a liberdade de viver e isso para nós é um problema, pois as pessoas ficam na incerteza.

Por meio da linguagem do personagem-narrador percebemos que há confronto de valores familiares. A apresentação do passado e do presente nos demonstra a amargura e a angústia de André, demonstrando uma contradição à ordem tradicional, que não apresenta o ideal, mas sim a fala do marginalizado.

[...] é um fato corriqueiro, querida Ana, pelo qual sempre passamos feito sonâmbulos, mas que, silencioso, é ainda o maior e o mais antigo escândalo: a vida só se organiza se desmentindo, o que é bom para uns é 
muitas vezes a morte para outros, sendo que só os tolos, entre os que foram atirados com displicência ao fundo, tomam de empréstimo aos que estão por cima a régua que estes usam pra medir o mundo; como vítimas da ordem, insisto em que não temos outra escolha, se quisermos escapar ao fogo deste conflito: forjarmos tranqüilamente nossas máscaras, desenhando uma ponta de escárnio na borra rubra que faz a boca; e, como resposta à divisão em anverso e reverso, apelemos inclusive para o deboche, passando o dedo untado na brecha do universo; se as flores vicejam nos charcos, dispensemos nós também o assentimento dos que não alcançam a geometria barroca do destino; não podemos nos permitir a pureza dos espíritos exigentes que, em nome do rigor, trocam uma situação precária por uma situação inexistente; de minha parte, abro mão inclusive dos filhos que teríamos, mas, na casa velha, quero gozar em dobro as delícias deste amor clandestino[...]. (NASSAR, 1989, p. 134$135)$.

Percebemos na obra que André quer liberdade de sentimentos reprimidos, que vão contra a ordem familiar imposta pelo pai. A linguagem demonstra um sistema de significações que aponta para a crise daquele personagem em relação ao mundo em que vive. A disposição dos membros à mesa da família simboliza uma tensão, do universo dos que se adaptam ou não à ordem estabelecida: ao lado direito do pai estão Pedro, Rosa, Zuleika e Huda; do esquerdo: a mãe, André, Ana e Lula. Percebemos também a artificialização na obra. O processo de substituição, criada por Sarduy, é presente no momento da caça às pombas, em que André expressa o seu desejo de amar Ana.

[...] e as pombas do meu quintal eram livres de voar, partiam para longos passeios mas voltavam sempre, pois não era mais do que amor o que eu tinha e o que eu queria delas, e voavam para bem longe e eu as reconhecia nos telhados das casas mais distantes entre o bando de pombas desafetas que eu acreditava um dia trazer também pro meu quintal imenso; ela estava lá,branco branco o rosto branco e eu podia sentir toda dubiedade, o tumulto e sua dores, e pude pensar cheio de fé eu não me engano neste incêndio, nesta paixão, neste delírio, e fiquei imaginando que para atraí-la de um jeito correto eu deveria ter tramado com grãos de uva uma trilha sinuosa até o pé da escada [...]. (NASSAR, 1989, p. 98, grifo nosso).

Quanto ao processo de condensação, com o jogo dos significados revela a questão da ordem e desordem, que para Sarduy (1979): “[...] assistimos à 'encenação' e à unificação de dois significantes que vêm reunir-se no espaço da tela, do quadro, ou no interior da memória." (SARDUY, 1979, p. 178-179). Percebemos isso claramente no monólogo, presente em toda a parte da Partida. 


\section{Considerações finais}

Lukács (2010) repudia o tecnicismo empobrecedor que reduz a arte à sua mais imediata manifestação estilística e com um vazio conteudista. Para Lukács (2010), o artista se distingue do não artista por sua capacidade de dar uma forma estética adequada a esse conteúdo histórico-social. O autor valoriza a importância de dar a cada assunto uma forma adequada.

Sob a perspectiva de Freire (1989), a compreensão e a leitura crítica do texto são decorrentes da compreensão do contexto em que a leitura se encontra. Dessa forma, compreender a visão do autor é fundamental para a compreensão da obra como um todo. A visão de mundo que Raduan Nassar (1989) imprime nas páginas de Lavoura Arcaica deixam nítido o momento social e cultural em que o autor estava inserido e também a maneira como ele enxergava as diversas questões que perpassavam a sociedade da época.

Vemos em Lavoura Arcaica um jogo neobarroco da enunciação, pela manipulação do discurso e dos sistemas de significação da narrativa, que nos direcionam para uma nova leitura; ficamos sabendo da história de uma família de imigrantes libaneses no interior do Brasil, demonstrando o amor, o incesto e a relação familiar.

A obra possibilitou-nos por fim verificar quais os valores presentes em nossa sociedade, diante de uma instituição tão forte como a família, verificando que determinados valores impostos podem não ser o verdadeiro e que existem pessoas diferentes, pensando de forma diferente. Acaba, pois, por mostrar uma visão do marginalizado e não uma visão do dominador, que não era usual nos romances tradicionais. O romance pós-moderno permite então uma nova dimensão, novos olhares e novas reflexões, pois demonstra o momento contemporâneo que talvez não nos é tão relatado, ou que talvez não queremos ver.

\section{REFERÊNCIAS}

BAKHTIN, Mikhail (Volochinov). Marxismo e filosofia da linguagem. São Paulo: HUCITEC, 1997.

CHIAMPI, Irlemar. Barroco e modernidade: ensaios sobre literatura latino-americana. São Paulo: Perspectiva/FAPESP, 1998. 
COELHO, Victor de Oliveira Pinto. A Lavoura Arcaica e a semente do mal: uma análise da obra de Raduan Nassar. Revista Eletrônica Literatura e Autoritarismo, Santa Maria, n. 16, p. 28-55, jul./dez., 2010.

FERREIRA, Nathalia Botura de Paula.; DUARTE, Newton. As artes na educação Integral: uma apreciação histórico-crítica. Revista Ibero-Americana de estudos em educação, v. 6, n. 3, p. 115-126, 2010.

FREIRE, Paulo. A importância do ato de ler: em três artigos que se completam. São Paulo: Autores Associados: Cortez, 1989.

LUKÁCS, George. Introdução a uma estética marxista. Sobre a particularidade como categoria estética. Rio de Janeiro: Civilização Brasileira, 1970.

LUKÁCS, George. Marxismo e a teoria da literatura. 2.ed. São Paulo: Expressão Popular, 2010.

NASSAR, Raduan. Lavoura Arcaica. 3.ed. São Paulo: Companhia das Letras, 1989.

NOGUEIRA JÚNIOR, Arnaldo (Org.). Projeto Releituras. 2016. Disponível em: <http://www.releituras.com/rnassar_bio.asp>. Acesso em: 16 set. 2016.

ROSENFELD, Anatol. Reflexões sobre o romance moderno. Texto/Contexto: São Paulo: Perspectiva, 1969.

ROSENTHAL, Erwin Theodor. A moderna concepção do mundo e Configuração e fragmentação. In: O Universo fragmentário. São Paulo: Companhia da Ed. Nacional, 1975.

SARDUY, Severo. O barroco e o neobarroco. In: MORENO, César Fernández (org.). América Latina em sua literatura. São Paulo: Perspectiva, 1979.

SIRINO, Salete Paulina Machado. Uma leitura literária e fílmica de lavoura arcaica. Revista Científica/FAP, Curitiba, v. 3, p. 163-182, jan./dez., 2008.

SÜSSEKIND, Flora. Literatura e vida literária. Rio de Janeiro: Jorge Zahar, 1985.

\section{Como referenciar este artigo}

FRANCO, Sandra Aparecida Pires.; GIROTTO, Cyntia Graziella Guizelim Simões.; MARIANO, Maria Luzia Silva. Lavoura arcaica de Raduan Nassar: uma possibilidade para a leitura do mundo contemporâneo. Revista Ibero-Americana de Estudos em Educação, Araraquara, v. 13, n. 2, p. 885-897, abr./jun., 2018. E-ISSN: 1982-5587. DOI: 10.21723/riaee.v13.n2.2018.9526

Submissão em: 10/03/2017

Aprovação final em: 02/07/2018 